\title{
Physical activity throughout adolescence and bone mineral density in early adulthood: the 1993 Pelotas (Brazil) Birth Cohort Study
}

\author{
R. M. Bielemann • M. R. Domingues • B. L. Horta • \\ A. M. B. Menezes • H. Gonçalves • M. C. F. Assunção • \\ P. C. Hallal
}

Received: 20 February 2014 / Accepted: 8 April 2014 /Published online: 30 April 2014

(C) The Author(s) 2014. This article is published with open access at Springerlink.com

\begin{abstract}
Summary Association between three physical activity (PA) measurements throughout adolescence and bone density at 18 years of age was investigated. PA was associated with both lumbar spine and femoral neck bone mineral density (BMD) in early adulthood independent of type of PA used in the analysis. The results were more consistent in boys.

Introduction This study amis to evaluate if PA during adolescence could influence BMD later in life.

Methods A population-based birth cohort study was carried out. PA was assessed at 11 and 15 years of age by questionnaire and included sports performed while BMD (lumbar spine and femoral neck) was measured by dual-energy X-ray absorptiometry at 18 years. A peak strain score was generated based on ground reaction forces of different PA. PA was measured as peak strain score, peak strain score multiplied by minutes/week and minutes/week. Unadjusted and adjusted analyses were performed using linear regression.

Results Overall, 3,811 adolescents were studied (1,866 boys and 1,945 girls). The peak strain score at 11 and 15 years was associated with lumbar and femoral neck BMD at 18 years in boys. Among girls, high-impact PA at 11 years was positively associated with lumbar and femoral $\operatorname{BMD}(p=0.01$; $p<0.001)$. After adjusted analysis, weekly minutes of PA at 11 years were not associated with lumbar spine but were associated with femoral neck BMD $(p<0.001)$; at 15 years,
\end{abstract}

R. M. Bielemann $(\bowtie) \cdot$ B. L. Horta • A. M. B. Menezes •

H. Gonçalves • M. C. F. Assunção • P. C. Hallal

Post-Graduate Program in Epidemiology, Federal University of

Pelotas, Rua Marechal Deodoro, $1160-3^{\circ}$ andar, CEP

96020-220 Pelotas, Rio Grande do Sul, Brazil

e-mail: renatabielemann@hotmail.com

M. R. Domingues $\cdot$ P. C. Hallal

Post-Graduate Program in Physical Education, Federal University of

Pelotas, Pelotas, Brazil weekly minutes of PA were positively associated with BMD at both sites. Regardless of PA status at 11 years of age, attaining the recommendations of PA (300 min/week) at 15 years appears to be important for BMD at 18 years in both sites in boys and girls. The results Appeared to be more consistent in boys. Conclusions PA during adolescence was positively associated with both lumbar spine and femoral neck BMD in early adulthood independent of type of PA used in the analysis.

Keywords Adolescence · Bone mineral density ·

Longitudinal studies $\cdot$ Physical activity

\section{Introduction}

Physical inactivity is responsible for 5.3 million deaths/year worldwide; $1 / 3$ of the world's adult population fails to achieve the recommended $150 \mathrm{~min} /$ week of physical activity (PA). In addition to its role in the prevention of noncommunicable diseases and premature mortality [1], particularly coronary heart disease, some types of cancer and type 2 diabetes [2], PA may delay the onset of osteoporosis, which is characterized by low bone mass and structural deterioration of bone tissue leading to increased risk of fractures [3].

A greater bone mass in early life is considered a critical factor in protecting against osteoporosis later in life [4]. It has been suggested that the relationship between PA and bone mass is regulated by hormonal factors (e.g., estrogen) in interaction with the impact on bones (mechanical factor) which change bone formation and reabsorption processes, increasing bone density $[5,6]$.

Although the growing skeleton of young people may benefit more, adults, with already formed skeletons, can also benefit from PA programs aimed at increasing the functional loads to which the bones are exposed [7]. However, there is 
evidence that critical years for skeletal growth and accumulation of bone mass are during the prepubertal and pubertal decade beginning around 10 years of age [8].

The association between PA and bone density, especially in cohort studies, has been evaluated using several measurement techniques. Most studies include overall PA, with no control for the impact of each activity [9]. Groothausen [10] proposed a classification of different activities according to the ground reaction force on bones. This classification considers four categories of activities - from no weight-bearing activities to those including jumping actions [10].

This study was aimed at evaluating the longitudinal association between PA during adolescence, evaluated by weekly time spent and two other measurements that assessed the impact based on Groothausen's classification [10] and bone mineral density (BMD) at 18 years in a population-based birth cohort.

\section{Methods}

This study was carried out with participants of the 1993 Pelotas (Brazil) Birth Cohort. Pelotas is a southern city in Brazil with $\sim 330,000$ inhabitants. In 1993, all five maternity hospitals were visited daily and all live borns whose mothers lived in the urban area were included in the cohort. Information was obtained on 5,249 live births. This study used information from the follow-ups that were carried out at the mean ages of 11, 15, and 18 years. More details on the methodology of this study have been published elsewhere [11, 12].

At 11 and 15 years of age, several strategies were used to locate the subjects (household visits based on the most recent address reported, information obtained during a school census, hospital records, city census, etc.). After locating the study participants, a household visit was performed by interviewers trained for 2 weeks in the application of a standardized and pretested questionnaire containing questions about several health related topics. At 18 years of age, cohort members were invited to visit the Epidemiologic Research Center, where participants were interviewed and submitted to several exams, including the dual-energy X-ray absorptiometry (DXA) method.

Leisure-time PA was assessed at the 11 and 15 follow-ups using a questionnaire developed for the study. This instrument was shown to be both reliable $(\mathrm{rho}=0.62)$ and valid (kappa $=$ 0.58 ) when compared with pedometer measurements [13]. PA was measured in these two follow-ups using a list of activities, which allows making inferences about the type of PA and its potential impact, besides the time spent in each activity. Adolescents were asked about their engagement in any PA (from a list with 13 options read by the interviewer) in the week prior to the interview. The instrument used at 11 years included the following activities: outdoor soccer, indoor football, athletics, basketball, dance, gymnastics, martial arts, swimming, volleyball, tennis, handball, trapper, and playing bat - the last two are games commonly practiced in southern Brazil. Other activities (not listed) could also be reported by the adolescent. For those activities not included in our list, information on frequency (days per week) and duration (hours and/or minutes per day) were collected. The same instrument was also used at 15 years of age. However, handball, trapper, and play bat, which had been asked at the 11 years follow-up, were replaced with walking, weight lifting, and fitness training.

Three scores of leisure-time PA were calculated. Firstly, time spent in PA was evaluated by multiplying frequency (days/week) by duration ( $\mathrm{min} /$ day). A total score ( $\mathrm{min} /$ week) of PA was then generated by adding weekly time spent in each activity. Next, PA was also analyzed using the peak strain score created by Groothausen [10]. Peak strain score consists of an evaluation of PA based on ground reaction forces of different PA. Activities with ground reaction forces of less than 1 times the body weight such as cycling and swimming have a peak score of 0 ; activities with peak score between 1 and 2 times the body weight - weight-bearing activities such as jogging, walking, and dancing - have a peak score of 1; activities with ground reaction forces between 2 and 4 times the body weight - including sprinting and turning actions such as tennis, aerobics, and soccer have a peak score of 2 , activities including jumping actions with ground reaction forces greater than 4 times the body weight such as basketball and gymnastics have a peak score of 3 . The peak scores of each activity were summed. The third variable was the sum of peak scores, as explained above, multiplied by the time spent in each activity.

All PA variables were initially evaluated in quartiles, to allow the comparability of coefficients. After, variation on PA was also evaluated. Those adolescents who spent at least $300 \mathrm{~min} /$ week in PA at each age were considered active. Therefore, adolescents could be categorized as: inactive at both ages, active only at 11 years, active only at 15 years and active at both ages. The same procedure was used in peak strain PA and in peak strain multiplied by the time spent in each PA. Finally, these variables were dichotomized using the highest tertile versus the lowest two tertiles.

At 18 years, BMD $\left(\mathrm{g} / \mathrm{cm}^{2}\right)$ was measured at the lumbar spine (L1-L4) and femoral neck using the method of DXA (Lunar Prodigy Advance (GE, Germany)). The analyses for femoral neck bone density were performed using only information of the right femur. Pregnant or suspected pregnant women, those subjects weighing more than $120 \mathrm{~kg}$ or with metal plates/screws inside the body or metal pieces (piercings, rings, or bracelets) that could not be removed were excluded of any DXA scan.

Other variables included in the analysis were sex, skin color, menarche age, and family income at birth. We also controlled the estimates to body mass index at 18 years because body size is highly correlated to bone mass. Standing height was 
Table 1 Description of physical activity at 11 and 15 years according to three different criteria in adolescents from the $1993 \mathrm{Pe}-$ lotas (Brazil) Birth Cohort

\begin{tabular}{|c|c|c|c|}
\hline & \multicolumn{3}{|c|}{ Physical activity measurement } \\
\hline & $\begin{array}{l}\text { Min/week } \\
\text { (mean (SD)) }\end{array}$ & $\begin{array}{l}\text { Peak strain score } \\
(\text { mean }(\mathrm{SD}))\end{array}$ & $\begin{array}{l}\text { Peak strain score } \times \\
\mathrm{min} / \text { week }(\text { mean }(\mathrm{SD}))\end{array}$ \\
\hline \multicolumn{4}{|l|}{ Boys } \\
\hline \multicolumn{4}{|l|}{11 years } \\
\hline 1st quartile & $6.8(12.2)$ & $0.1(0.3)$ & $2.6(8.8)$ \\
\hline 2nd & $117.8(44.7)$ & $2.2(0.4)$ & $172.5(75.2)$ \\
\hline $3 \mathrm{rd}$ & $314.0(76.1)$ & $4.8(0.8)$ & $523.4(140.0)$ \\
\hline 4th quartile & $987.8(606.6)$ & $8.9(2.2)$ & $1,808.3(1,211.5)$ \\
\hline \multicolumn{4}{|l|}{15 years } \\
\hline 1st quartile & $0.6(3.1)$ & $0.0(0.0)$ & $0.0(0.0)$ \\
\hline 2nd & $109.3(48.8)$ & $1.8(0.4)$ & $156.1(70.2)$ \\
\hline $3 \mathrm{rd}$ & $336.8(86.7)$ & $3.5(0.5)$ & $505.7(141.0)$ \\
\hline 4th quartile & $1,094.2(585.8)$ & $6.3(1.7)$ & $1,765.0(1,020.4)$ \\
\hline \multicolumn{4}{|l|}{ Girls } \\
\hline \multicolumn{4}{|l|}{11 years } \\
\hline 1st quartile & $6.8(12.5)$ & $0.2(0.4)$ & $2.8(9.5)$ \\
\hline 2 nd & $110.8(43.7)$ & $2.6(0.5)$ & $161.7(73.2)$ \\
\hline $3 \mathrm{rd}$ & $304.2(76.7)$ & $5.0(0.7)$ & $506.2(133.2)$ \\
\hline 4th quartile & $933.3(544.0)$ & $8.9(2.2)$ & $1,746.0(1,273.8)$ \\
\hline \multicolumn{4}{|l|}{15 years } \\
\hline 1st quartile & $0.6(3.2)$ & $0.0(0.0)$ & $0.0(0.0)$ \\
\hline 2nd & $104.0(48.7)$ & $1.2(0.4)$ & $129.5(65.7)$ \\
\hline $3 \mathrm{rd}$ & $310.9(83.2)$ & $3.4(0.5)$ & $463.3(139.8)$ \\
\hline 4th quartile & $908.8(487.6)$ & $6.5(1.8)$ & $1,627.2(1,118.8)$ \\
\hline
\end{tabular}

measured to the nearest $1 \mathrm{~mm}$ with barefooted subjects using a wooden stadiometer whereas weight was obtained using a scale coupled to BodPod ${ }^{\circledR}$ (Cosmed, Italy) equipment.

All statistical analyses were stratified by sex. Potential effect modification was considered when the $\mathrm{p}$-value for the interaction term was $<0.2$. Unadjusted and adjusted analyses were performed using linear regressions and $p$ values were obtained by Wald's test for heterogeneity. Adjusted analysis included all confounders listed previously according to age of exposure (i.e., 15 years exposures were not considered for the 11 years follow-up analyses). The significance level was set at $5 \%$. The analyses were performed with Stata 12 software (StataCorp, College Station, TX, USA).

All phases of this study were approved by the Ethics Committee of the Medicine School of the Federal University of Pelotas. Written informed consent was obtained from every subject prior to the interviews.

\section{Results}

At 18 years, we managed to interview 4,106 subjects and information on PA peak strain information was gathered from 3,811 adolescents (1,866 boys and 1,945 girls) from the 1993
Pelotas (Brazil) Birth Cohort in the two earlier visits (11 and 15 years). Overall results are only shown for PA and peak strain (Table 1) because boys and girls present very distinct bone health profiles. Table 1 also shows the score obtained by multiplying PA in minutes and peak strain.

Among boys (Table 2), peak strains at 11 and 15 years were positively associated with lumbar and femoral neck bone density at 18 years; more specifically, PA peak strain at 15 years resulted in larger effects at the femoral neck site. PA in minutes had similar effects. We did not observe associations between PA time $\times$ impact score at 11 and lumbar BMD, but femoral neck bone density was positively associated with the score $(p=0.004)$. At the age of 15 , the score was positively associated with both lumbar and femoral BMD at 18 years in boys $(p<0.001)$. The coefficients were slightly larger when impact at the age of 15 is considered. Apparently, in boys, the age when activity is performed is more important than the impact generated by the activity.

The analyses among girls (Table 3) showed that highimpact PA at 11 years was positively associated with lumbar and femoral BMD. Impact PA at 15 was not associated with lumbar spine BMD but was associated with femoral neck bone density $(p=0.005)$. All coefficients were higher for PA impact at 11 years. 


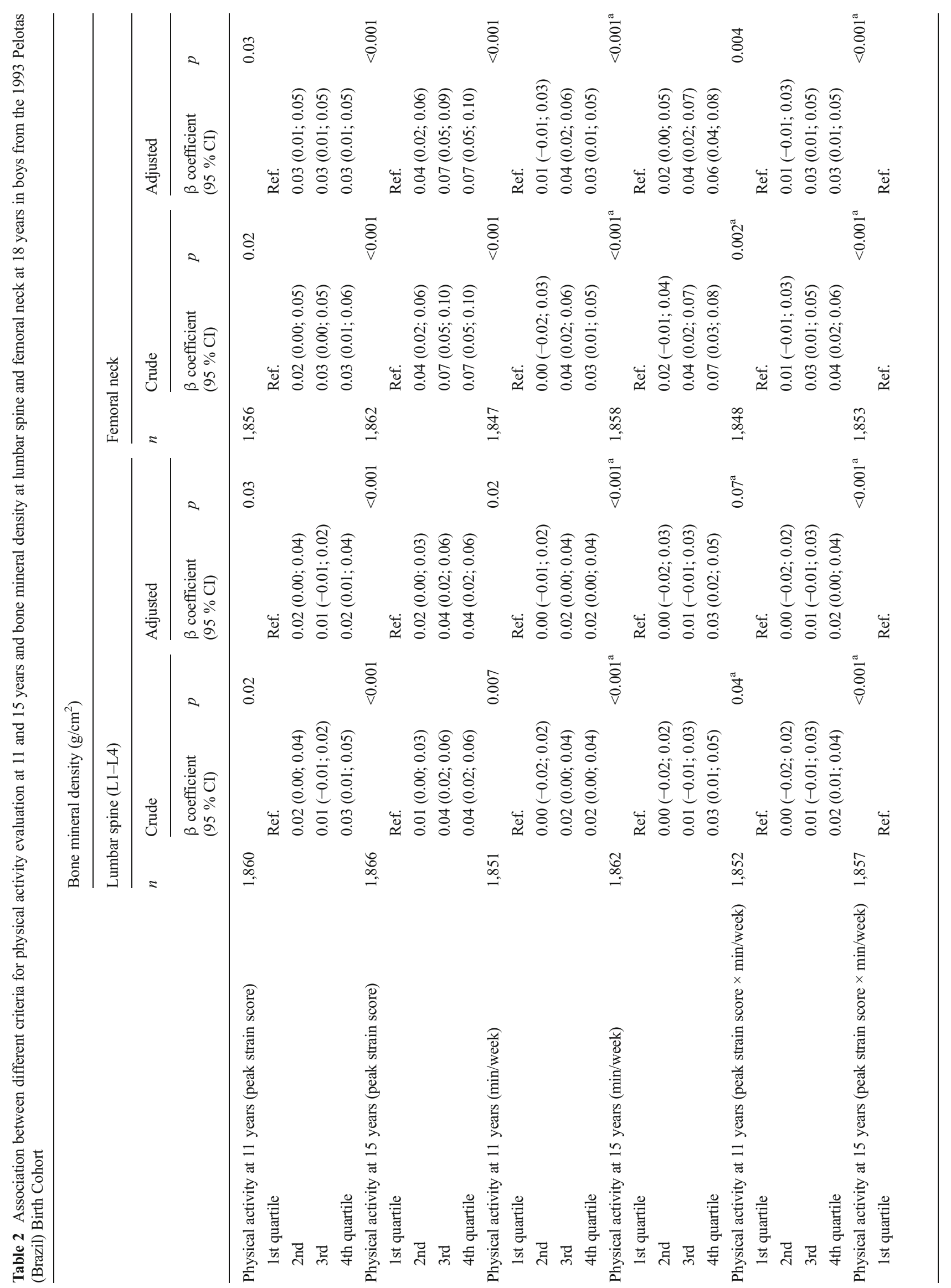


After controlling for confounding variables, PA (weekly minutes) at 11 years was not associated with lumbar spine bone density but was positively associated with femoral neck bone density $(p<0.001)$. Weekly minutes of PA at 15 years were positively associated with BMD at both sites (lumbar spine: $p=0.04$; femoral neck: $p=0.046$ ). The weekly minutes of PA coefficients at 11 and 15 years were similar for both sites. The impact $\times$ time PA score in girls at both ages was only positively associated with femoral neck bone density (11 years: $p<0.001 ; 15$ years: $p=0.003$ ). We could not detect associations between the score and lumbar spine. The femoral neck coefficients were similar for activities performed at both ages.

Changes in PA patterns during adolescence and their effects were also assessed and are displayed in Fig. 1. In boys, we observed that being active only at 11 was not associated to $\mathrm{BMD}$, except when the impact $\times$ time is considered (femoral neck only). The most important effect was detected when boys were active or belonged to the highest tertile at both ages.

Girls presented the same pattern observed in boys. However, it appearss that belonging to the highest impact tertile at 11 years was positively associated with higher bone density at both sites. Moreover, belonging to the highest tertile of PA, regardless of impact, was positive for femoral neck site bone density.

\section{Discussion}

We observed a positive association between PA at early/midadolescence and lumbar spine and femoral neck BMD in early adulthood in individuals belonging to the 1993 Pelotas (Brazil) Birth Cohort. PA at 11 years was positively associated with lumbar spine bone density in girls only when the peak strain was considered. In boys, regression coefficients appear to be higher for PA at 15 years, whereas among girls the coefficients were similar at both ages. Associations were more consistent for femoral neck bone density. With respect to the variation in PA from 11 to 15 years of age, overall, being active or belonging to the highest tertile of PA (or peak strain score) only at 11 years was not associated with bone density among boys. Conversely, in girls, it appearss important to take into account the peak strain score at 11 years for the bone density in the future though the same was not found when only the weekly time spent in PA was considered. Attaining the current recommendations of PA (300 min/week) at 15 years appearss to be positively important for bone density at 18 years in both anatomical sites, regardless of PA status at 11 years of age. However, in PA measurements, considering the peak strain score, belonging to the highest tertile of peak strain or peak strain $\times \min /$ week at 11 years of age was positively associated with higher bone density at both sites, whereas belonging to the highest tertile of these measurements 


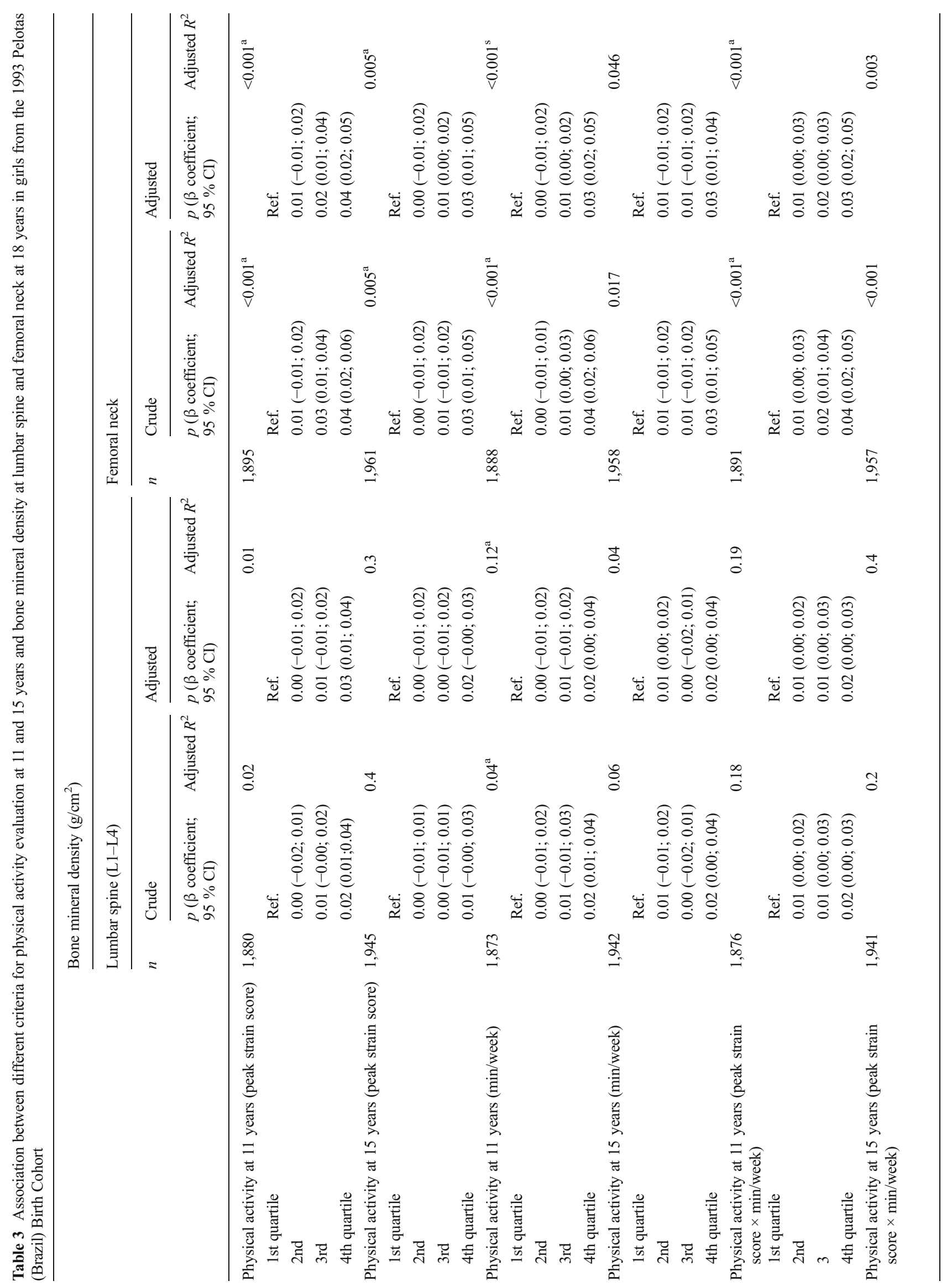




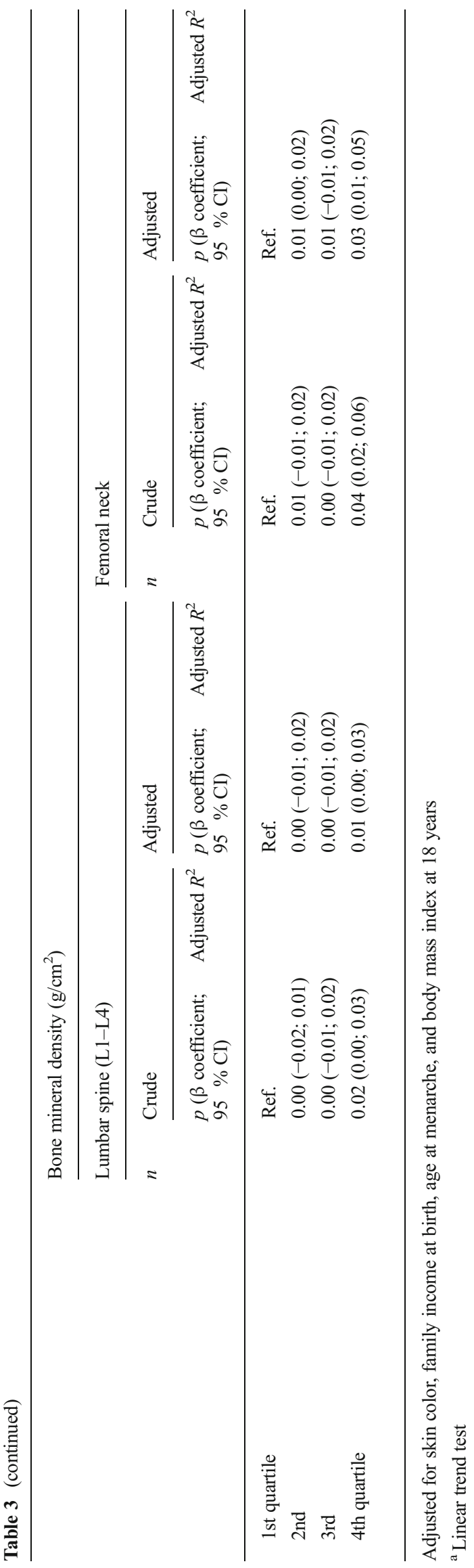

only at 15 years or in both ages was positively associated with bone density only at femoral neck site.

Longitudinal analyses about this subject are scarce, particularly derived from low- and middle-income countries. Such studies are important because PA patterns and confounders are distinct between rich and poor countries [14]. The possibility of making inferences using three different PA measurements is another strength of the study. However, there is no available information about calcium intake in our sample, impeding us to include it as a confounder in the regression models.

In general, coefficients were higher when PA considered the peak strain as an exposure in boys, whereas we did not observe such trend among girls. The mean PA measured with peak strain score was higher in males than in females, as well as the weekly time spent in PA. However, previous study suggests that boys' bones are more sensitive to loading than girls' [15].

Similar prospective studies are scarce. Previous crosssectional analysis performed by McVeigh et al. [16] in 9year-old South African children belonging to the "Birth to Twenty" cohort study used similar PA measurements. In both PA measurements, white children in the highest quartile showed greater BMD than children in the lowest quartile of PA measurements. The lack of association in black children was attributed to lower levels of PA among them [16].

Another study carried out with individuals from the Amsterdam Growth and Health Longitudinal Study (AGAHLS) used PA as weighted metabolic score of intensity, frequency, and duration and PA as the sum of peak score only [17]. Different from our results in boys, Kemper et al. did not found any relationship between lumbar spine bone density at 32 years of age and PA peak strain score during adolescence. Conversely, lumbar spine bone density was positively associated with PA measurement without peak strain score during adolescence. When the analysis was performed using PA during adulthood, PA evaluated as the sum of peak strain score showed higher regression coefficient in association with lumbar spine bone density [17].

There is some evidence that bone adaptation is limited to loading regions [18]. This may explain the consistency of findings for femoral neck bone density but not for lumbar spine bone density, independent of the PA measurement. This positive effect of PA on femoral neck bone density is important because hip fractures account for the majority of fracturerelated health care expenditure and losses in quality-adjusted life years in men and women over the age of 50 years [19].

The osteogenic benefits of PA are dependent on age and the relative risk of fracture [20] and puberty has significant influences on changes in skeletal mass [4]. A recent systematic review found that PA during adolescence was associated with higher values of bone density in young adulthood [9], when the maximal peak of bone mass is attained, at least in males. A $10 \%$ higher peak bone mass can reduce the risk of fracture by 


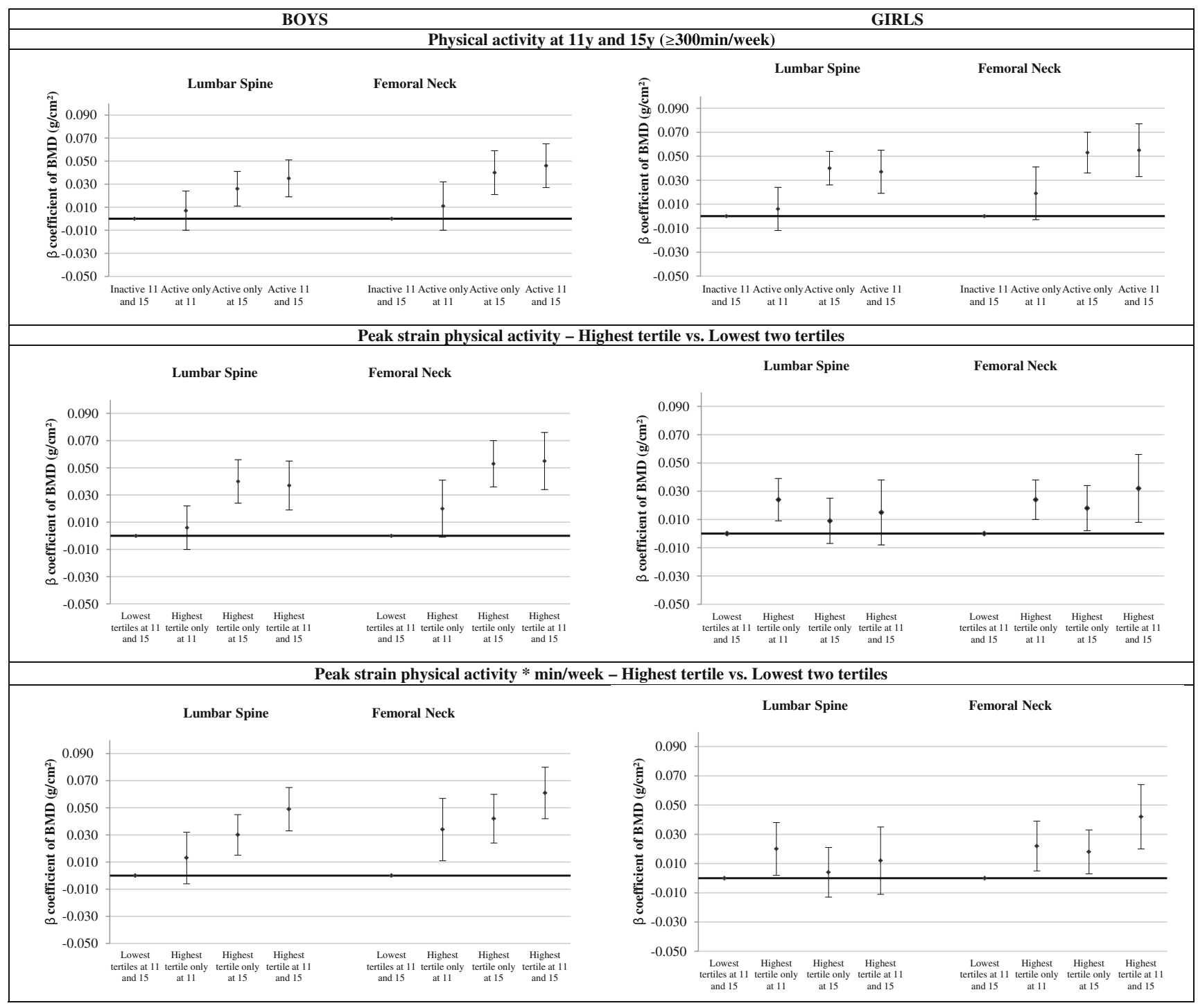

Adjusted for skin color, family income at birth, age at menarche and body mass index at $18 \mathrm{y}$.

Fig. 1 Association between change on PA from 11 to 15 years according to different criteria and bone mineral density at 18 years in members of the 1993 Pelotas (Brazil) Birth Cohort

$50 \%$ and delay the development of osteoporosis by 13 years [21, 22].

The time of peak bone gain is approximately 12.5 years in girls and 14.1 in boys. On average, $26 \%$ of total adult bone mass is gained during a 2-year period [23]. Our PA measurements were at 11 and 15 years of age. The last was close to the age of peak bone gain in boys whereas in girls the measurements were before and after average peak bone gain. This may help to explain the consistency of findings in boys, appointing to higher importance for PA at 15 years of age, independent of the PA measurement used. In addition, this may help explain the inconsistency of findings in girls.

We conclude that PA in early and middle adolescence was positively associated with both lumbar spine and femoral neck BMD in early adulthood. Association between PA and bone density was higher for the femoral neck anatomical site and being active at 15 years appears to be more important for increases in bone density at least in boys. Findings in femoral neck showed that active girls at both 11 and 15 years had increased BMD at this anatomical site at 18 years. In boys, the regression coefficients were higher when PA used the peak strain score in the measurement, drawing attention to importance of loading in the PA. These individuals will be monitored, and future assessments will be carried out during adulthood.

\section{Conflicts of interest None.}

Open Access This article is distributed under the terms of the Creative Commons Attribution Noncommercial License which permits any noncommercial use, distribution, and reproduction in any medium, provided the original author(s) and the source are credited. 


\section{References}

1. Lee IM, Shiroma EJ, Lobelo F, Puska P, Blair SN, Katzmarzyk PT (2012) Effect of physical inactivity on major non-communicable diseases worldwide: an analysis of burden of disease and life expectancy. Lancet 380(9838):219-229. doi:10.1016/S0140-6736(12) 61031-9S0140-6736(12)61031-9

2. World Health Organization (2004) Comparative quantification of health risks: global and regional burden of disease attributable to selected major risk factors. Geneva

3. U.S. Department of Health and Human Services (2004) Bone health and osteoporosis: a report of the Surgeon General. Rockville, MD

4. Anderson JJ (2000) The important role of physical activity in skeletal development: how exercise may counter low calcium intake. Am J Clin Nutr 71(6):1384-1386

5. Lanyon LE (1993) Osteocytes, strain detection, bone modeling and remodeling. Calcif Tissue Int 53(Suppl 1):S102-S106, discussion S106-107

6. Kemper HCG (2000) Skeletal development during childhood and adolescence and the effects of physical activity. Pediatr Exerc Sci 12: 198-216

7. Zernicke R, MacKay C, Lorincz C (2006) Mechanisms of bone remodeling during weight-bearing exercise. Appl Physiol Nutr Metab 31(6):655-660. doi:10.1139/h06-051

8. Bonjour JP, Theintz G, Buchs B, Slosman D, Rizzoli R (1991) Critical years and stages of puberty for spinal and femoral bone mass accumulation during adolescence. J Clin Endocrinol Metab 73(3):555-563

9. Bielemann RM, Martinez-Mesa J, Gigante DP (2013) Physical activity during life course and bone mass: a systematic review of methods and findings from cohort studies with young adults. BMC Musculoskelet Disord 14:77. doi:10.1186/1471-2474-14-771471-2474-14-77

10. Groothausen J, Siemer H, Kemper HCG, Twisk J, Welten DC (1997) Influence of peak strain on lumbar bone mineral density: an analysis of 15-year physical activity in young males and females. Pediatr Exerc Sci 9:159-173

11. Victora CG, Araujo CL, Menezes AMB, Hallal PC, Vieira MFA, Neutzling MB, Gonçalves H, Valle NJ, Lima RC, Anselmi L, Behague DP, Gigante DP, Barros FC (2006) Methodological aspects of the 1993 Pelotas (Brazil) Birth Cohort Study. Rev Saude Publica 40(1):39-46

12. Victora CG, Hallal PC, Araujo CL, Menezes AMB, Wells JC, Barros FC (2008) Cohort profile: the 1993 Pelotas (Brazil) Birth Cohort Study. Int J Epidemiol 37:704-709. doi:10.1093/ije/dym177
13. Bastos JP, Araujo CL, Hallal PC (2008) Prevalence of insufficient physical activity and associated factors in Brazilian adolescents. J Phys Act Health 5(6):777-794

14. Batty GD, Alves JG, Correia J, Lawlor DA (2007) Examining lifecourse influences on chronic disease: the importance of birth cohort studies from low- and middle- income countries. An overview. Braz J Med Biol Res 40(9):1277-1286

15. Kriemler S, Zahner L, Puder JJ, Braun-Fahrlander C, Schindler C, Farpour-Lambert NJ, Kranzlin M, Rizzoli R (2008) Weight-bearing bones are more sensitive to physical exercise in boys than in girls during pre- and early puberty: a cross-sectional study. Osteoporos Int 19(12):1749-1758. doi:10.1007/s00198-008-0611-5

16. McVeigh JA, Norris SA, Cameron N, Pettifor JM (2004) Associations between physical activity and bone mass in black and white South African children at age 9 yr. J Appl Physiol (1985) 97(3): 1006-1012. doi:10.1152/japplphysiol.00068.200400068.2004

17. Kemper HC, Bakker I, Twisk JW, van Mechelen W (2002) Validation of a physical activity questionnaire to measure the effect of mechanical strain on bone mass. Bone 30(5):799-804

18. Guadalupe-Grau A, Fuentes T, Guerra B, Calbet JA (2009) Exercise and bone mass in adults. Sports Med 39(6):439-468. doi:10.2165/ 00007256-200939060-000022

19. Strom O, Borgstrom F, Kanis JA, Compston J, Cooper C, McCloskey EV, Jonsson B (2011) Osteoporosis: burden, health care provision and opportunities in the EU: a report prepared in collaboration with the International Osteoporosis Foundation (IOF) and the European Federation of Pharmaceutical Industry Associations (EFPIA). Arch Osteoporos 6(1-2):59-155. doi:10.1007/s11657-011-0060-1

20. Ebeling PR, Daly RM, Kerr DA, Kimlin MG (2013) An evidenceinformed strategy to prevent osteoporosis in Australia. Med J Aust 198(2):90-91. doi:10.5694/mja12.11363

21. Cummings SR, Black DM, Nevitt MC, Browner W, Cauley J, Ensrud K, Genant HK, Palermo L, Scott J, Vogt TM (1993) Bone density at various sites for prediction of hip fractures. The Study of Osteoporotic Fractures Research Group. Lancet 341(8837):72-75

22. Hernandez CJ, Beaupre GS, Carter DR (2003) A theoretical analysis of the relative influences of peak BMD, age-related bone loss and menopause on the development of osteoporosis. Osteoporos Int 14(10):843-847. doi:10.1007/s00198-003-1454-8

23. Bailey DA, McKay HA, Mirwald RL, Crocker PR, Faulkner RA (1999) A six-year longitudinal study of the relationship of physical activity to bone mineral accrual in growing children: the university of Saskatchewan bone mineral accrual study. J Bone Miner Res 14(10): 1672-1679. doi:10.1359/jbmr.1999.14.10.1672 